\title{
Study on the Reserve Scale of Light Weapons
}

\author{
Jian $\mathrm{Gao}^{1,2}$, Tielin Liu ${ }^{1, *}$, Yongle $\mathrm{Wu}^{1}$ and Liang Zhang ${ }^{2}$ \\ ${ }^{1}$ Department of Equipment Command and Administration Army Engineering University, Shijiazhuang, China \\ ${ }^{2}$ Unit 65154 PLA, Chaoyang, China \\ ${ }^{*}$ Corresponding author
}

\begin{abstract}
In view of the current lack of practical light weapons reserve model research, through the analysis of factors and the effort on combing related concepts, a light weapons reserve military conceptual model and mathematical model have been established, which provides a reference for decision-making and light weapons reserve requirement demonstration.
\end{abstract}

Keywords—light weapon; reserve scale; model

\section{RELATED CONCEPTS}

With the increasing level of science and technology and the level of industrial production, the speed of renewal and elimination of light weapons is accelerating, which makes it more and more important to reserve light weapons. The scientific and appropriate reserve of light weapons is an important part of the preparation of military combat equipment, which is related to the maintenance and recovery of the combat effectiveness of the army ${ }^{[1]}$.

However, although our army's equipment is developing rapidly, the research on the scale of the small arms is lagging behind. In the long run, there is a lack of special research on the scale model of the small arms reserves, which makes the argumentation of its reserve scale unscientific and unreasonable $\mathrm{e}^{[2-3]}$. Therefore, actively adapt to the needs of the times, it is urgent to carry out the research on the scale model of the light weapons reserve.

\section{A. War Materials Reserve}

The reserve of readiness materials refers to the reserve of materials in advance to ensure the timely response to the needs of the war and emergency. It refers to the security forces quickly into combat, linked to material supply follow-up material reserves, divided into strategic reserves, reserves and reserve battle tactics, including weapons, vehicles, ammunition, fuel, supplies, and packed medicinal materials, repair parts and other special material equipment etc.

\section{B. Light Weapon Reserve}

Small arms and equipment reserve refers to the planned storage of light weapons in advance for the purpose of ensuring the training, operational readiness and operational needs of the army. It is an important part of the preparation of materials for the small arms and equipment, and is also an important material basis for ensuring the war needs ${ }^{[4]}$.

\section{Light Weapons Reserve Scale}

The size of the reserve of light weapons usually refers to the amount of the physical reserve of light weapons, which is the key and difficult point in the study of the issue of the reserve of light weapons. The argumentation of the scale of light weapons depends mainly on establishing models, that is, using models instead of system prototypes to abstract solutions, which are mainly divided into military conceptual models and mathematical models ${ }^{[5]}$.

\section{Military Conceptual Model of Light WeApon RESERVE SCALE}

The establishment of a military conceptual model is the first step to abstract the related contents of the scale of light weapons. The first step is to analyze and comb the meaning of relevant concepts, define the important process of its connotation and denotation. And it is also the important foundation for building mathematical models.

\section{A. Analysis of Light Weapon Reserve Scale Affecting Factors}

The analysis of influencing factors is the basis for establishing a military conceptual model. The factors affecting the scale of our small arms include our army's current military guiding principles, strategic policies and policies, future wars and characteristics of small arms, the difficulty of storage and supply, etc. Because these factors are difficult to be quantified, they can not be embodied in the military conceptual model, and they are referred to as "qualitative" factors ${ }^{[6]}$.

In addition to the qualitative factors, the production capacity of light weapons is also the main factor affecting the scale of its reserve. The three aspects of the stockpile, production and demand of the small arms are interdependent. Reserves provide demand for demand, demand provides impetus for production, and production provides a supplement for reserves. If the light weapons, high production efficiency, short cycle, strong continuity, then reduce the physical reserves can meet the equipment requirements, core idea of "zero inventory" concept is by increasing the material flow in the supply chain to reduce the reserve scale even cancelled the reservation $\operatorname{link}^{[7]}$. 


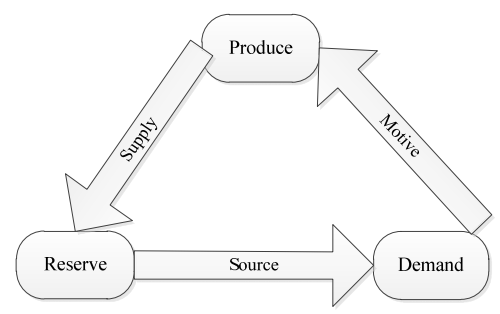

FIGURE I. RELATION DIAGRAM OF RESERVE PRODUCTION AND DEMAND.

However, with the development of the whole life of our army in the light weapons, it is not difficult to find that the light weapons are "non consumable material. Equipment consumption is relatively small and our army did not establish and maintain production factory equipped with a large number of light weapons, so relying on production capacity is insufficient to meet the demand for light weapons. Therefore, the demand of our army's light weapons and equipment mainly depends on the physical reserve, and the production capacity is mainly used to supplement the consumption of physical reserve ${ }^{[8]}$

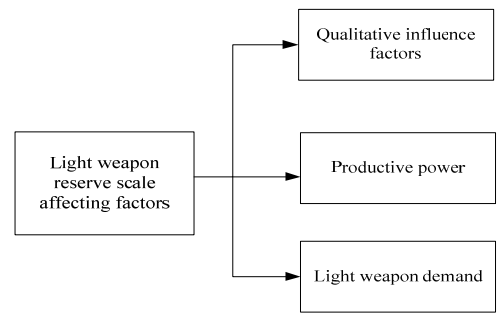

FIGURE II. THE IMPACT FACTOR OF LIGHT WEAPON RESERVE SCALE.

\section{B. Analysis of Demand for Light Weapons}

Through analysis, we can see that the scale of light weapons depends mainly on the demand for light weapons, and the scale of small arms is also transformed into the demand demonstration of light weapons. As a part of the military material reserve, the demand for light weapons can be divided into daily demand, combat readiness and readiness insurance. Among them, the daily demand mainly refers to meet the turnover demand of light weapons daily training and regular damage, scrapping and so on, mainly depends on daily consumption, and daily consumption rate. The war readiness insurance amount refers to a certain degree of insurance reserve that is maintained to maintain certain strategic deterrence and continuous operational readiness after the end of the war, and it can also be used to supplement the shortage of combat readiness in every campaign direction, which is mainly related to the insurance reserve coefficient.

Total demand $=$ Daily demand + Readiness insurance + Combat readiness demand

Daily demand $=$ Compiling number $\times$ Daily consumption rate $(2)$
Combat readiness number $=$ Existing equipment $\times$ Insurance reserve coefficient

The demand for combat readiness of light weapons can be divided into operational consumption, operational loss and operational mobility. Loss refers to the reduction of combat readiness caused by the consumption of non direct use, and it can be solved through operational consumption and estimated loss rate. Mobile volume refers to a certain degree of mobile material reserve to cope with unexpected and special needs, and it can be solved through the ratio of operational consumption and mobile volume.

Combat demand $=$ Loss + Maneuver number + Combat consumption

The amount of loss $=$ Operational consumption $\times$ Loss rate

Maneuver number $=$ Operational consumption $\times$ Ratio coefficient of maneuver

\section{Analysis of Light Weapon Operational Consumption}

To sum up, the operational consumption of light weapons is the key to calculate the demand for arms of light weapons and to solve the scale of its reserve. Combat consumption refers to in order to achieve the objective of the operation, the number of used to wipe out the enemy's effective strength, destroy enemy equipment, destroy target and interference of local military action to direct or indirect consumption of goods.

The consumption of light weapons in a specific military operation is the object of study. First, the consumption of light weapons is related to the number of light weapons in the armed forces. The number of small arms involved in war is directly related to the consumption of light weapons, and the number of war equipment needs to refer to the number of small arms in the army. Secondly, the consumption of light weapons is related to the war damage rate of wartime and small arms. The rate of war loss refers to the ratio of the number of equipment loss to the total number of combat equipment after the end of one operation or in a certain time of operation, usually expressed in percentage. Third, the operational consumption of light weapons is related to the degree of damage to light weapons in wartime. The number of war damaged weapons can be obtained though the introduction of the compilation number and the war loss rate, but the amount of war damage is not equal to the amount of combat consumption. The statistics of the number of small arms damaged by war include various damage levels, and the number will be larger than the operational consumption we need to demonstrate here. This is because not all war losses need to be replenish through the small arms reserve. The damage of light weapons can also restore the technical and tactical performance of small arms through maintenance and replacement of spare parts. Therefore, in order to calculate the operational consumption, we have introduced the corresponding damage ratio coefficient, where the "corresponding" means in the battlefield environment, its 
performance cannot be recovered in a short time through the equipment maintenance, the need to rely on light weapons equipment reserve to replace and supplement can play a role in the battlefield, usually light weapons of scrap and heavy loss degree accounted for all the proportion of loss of light weapons of war.

One battle consumption $=$ Compiling $\times$ War loss rate $\times$ Ratio coefficient

\section{MATHEMATiCAL MOdEL OF Light WeAPON RESERVE SCALE}

Many factors affect the light weapons reserve scale demonstration involved, can not use the precise mathematical model expression, so the impact by excluding qualitative factors and production capacity, the problem is transformed into a light weapons demand forecasting, the establishment of light weapons demand mathematical model combined with other factors of light weapons reserves.

\section{A. The Establishment of the Model}

The consumption of light weapons to fight a battle as the logical starting point, according to from the "battle light weapons consumption" to "battle light weapons combat demand" and "light weapons combat demand" to "light weapons demand" thought, to the military conceptual model for based on mathematical model.

According to(4)(5)(6)(7), $\quad \mathrm{M}_{\mathrm{a}}=\mathrm{b} \cdot \mathrm{z} \cdot \omega ; \quad \mathrm{M}_{\mathrm{z}}=\mathrm{M}_{\mathrm{a}}+\mathrm{M}_{\mathrm{b}}+\mathrm{M}_{\mathrm{c}}$; $\mathrm{M}_{\mathrm{b}}=\mathrm{M}_{\mathrm{a}} \cdot \omega_{\mathrm{b}} ; \mathrm{M}_{\mathrm{c}}=\mathrm{M}_{\mathrm{a}} \cdot \omega_{\mathrm{c}} ; \mathrm{M}_{\mathrm{z}}=\mathrm{b} \cdot \mathrm{z} \cdot \omega \cdot\left(1+\omega_{\mathrm{b}}+\omega_{\mathrm{c}}\right)$

Among them, $\mathrm{M}_{\mathrm{z}}$ represents a battle light weapons combat demand; $b$ represents the number of troops prepare battles fought light weapons; $\mathrm{z}$ on behalf of the battle of light weapons damage rate; $\omega$ represents the proportionate coefficient of the damage degree of "heavy loss and scrap" of the battle light weapons in the campaign; $\omega_{\mathrm{b}}$ represents the loss rate of light weapons; $\omega_{\mathrm{c}}$ represents the proportion of motor light weapons coefficient.

A battle of light weapons demand is expected to expand to the army of light weapons readiness needs, need to consider the main combat direction at the same time and have the possible multiple battles light weapons readiness needs, the total amount of light weapons required but not their simple addition, but considering the importance of each battle, the coordination between the various battle the deployment of light weapons and other factors, so according to the specific needs, setting the corresponding adjustment coefficient for light weapons combat demand I battle in total demand for combat readiness.

According to (8), $\mathrm{M}_{1}=\sum_{i=1}^{n} M_{i} \mu_{i}=\sum_{i=1}^{n} b_{i} z_{i} \omega_{i}\left(1+\omega_{\mathrm{c}}+\omega_{\mathrm{b}}\right) \mu_{i}$

Among them, $\mathrm{M}_{\mathrm{i}}$ represents the battle light weapons combat demand; $M_{1}$ represents the army light weapons combat demand; $i$ is expected to total military readiness needs light weapons, the number of the campaign should consider $\mathrm{i}=, 1,2,3$. $\mathrm{n} ; \mathrm{b}_{\mathrm{i}}$ represents the battle War Forces light weapons establishment; $\mathrm{z}_{\mathrm{i}}$ represents the battle light weapons damage rate; $\omega_{b}$ represents the loss rate of light weapons; $\omega_{c}$ represents the proportion of motor light weapons on behalf of the coefficient; $\mu_{i}$ is the battle readiness light weapons demand adjustment coefficient.

$$
\begin{aligned}
& \text { According to }(1)(2)(3)(9), \quad \mathrm{M}=\mathrm{M}_{1}+\mathrm{M}_{2}+\mathrm{M}_{3} ; \quad \mathrm{M}_{2}=\mathrm{b} \cdot \omega_{2} ; \\
& \mathrm{M}_{3}=\mathrm{b} \cdot \omega_{3}, \mathrm{M}=\mathrm{b} \cdot \omega_{2}+\mathrm{b} \cdot \omega_{3}+\sum_{i=1}^{n} b_{i} z_{i} \omega_{i}\left(1+\omega_{\mathrm{c}}+\omega_{\mathrm{b}}\right) \mu_{i}
\end{aligned}
$$

Among them, $M$ represents the total demand of light weapons; $b$ represents the army light weapons establishment; $\omega_{2}$ represents daily consumption of light weapons; $\omega_{3}$ represents the insurance reserve insurance representatives light weapons; i represents the expected military readiness light weapons demand, need to consider the number of battle, $i=$ $1,2,3 \mathrm{n} ; \mathrm{b}_{\mathrm{i}}$ represents the battle War Forces light weapons establishment; $z_{i}$ represents the I battle of light weapon damage rate; $\omega_{i}$ represents the I battle light weapon damage coefficient; $\omega_{\mathrm{b}}$ represents the loss of light weapons; $\omega_{\mathrm{c}}$ represents the amount of motor loss rate; $\mu_{i}$ represents adjustment coefficient light weapons combat demand.

\section{B. The Explanation of the Model}

While the qualitative factors can not be reflected in the mathematical model, the insurance reserve coefficient, volume ratio and motor adjustment coefficient have great uncertainty, subjectivity and confidentiality, so the model does not need to give a precise light weapons total reserves data, it only provides a reference for decision-making and light weapons reserve requirement demonstration.

\section{REFERENCES}

[1] Li Xuening, Dejun Howe. Thinking about the development of China's light weapons in the early twenty-first Century, [J]. light weapons, 2000 (9).

[2] Chen Yu, Wu Li. Application of neural network in the research of equipment reserve scale [C]. China Joint Academic Conference on fuzzy logic and computational intelligence. 2005.

[3] Yao Kay, Guo Shizhen, Fu Xiaozhong, and so on. The scale control model of ammunition physical reserve construction $[\mathrm{J}]$. equipment college journal, 2016, 27 (1): 52-56.

[4] Summer Changchun. Elementary introduction to the direction of the development of light weapons technology [J]. scientists, 2017 (3): 18-19.

[5] Hu Bin, evergreen. Practice analysis and Research on model modeling of military concept model [J]. system simulation, 2008, 20 (12): 3085-3088.

[6] Jiang Da. Military logistics system model and application of [M]. Chinese material press, 2006.

[7] He Jianfeng, Li Cui. New high, future war weapons and equipment production capacity on the construction of [J]. automation, 2014 (10): 46.

[8] Li Xiaosong, Lv Bin, Shu Shaogan, et al. Research on research and production capacity generation of military and civilian integrated weapons and equipment, Journal of [J]. equipment college, 2013 (6): 3134 